\title{
VOLATILE COMPOUNDS IDENTIFIED AND QUANTIFIED IN MOLDOVA'S WINES
}

\author{
Ioana, REBENCIUC ${ }^{1}$, Ovidiu, TIȚA ${ }^{2 *}$, Diana Ionela, POPESCU ${ }^{3}$ \\ 1"Stefan cel Mare" University of Suceava, 13 University Street, Suceava, Romania \\ 2"Lucian Blaga” University of Sibiu, 10 Victoriei Boulevard, Sibiu, Romania *corresponding author: ovidiu.tita@ulbsibiu.ro \\ ${ }^{3}$ National Research and Development Institute for Cryogenics and Isotopic Technologies - ICSI Ramnicu Valcea, Romania,
}

\begin{abstract}
In this paper we studied and characterized four wines from the grape varieties Busuioaca de Bohotin, Feteasca neagră, Muscat Ottonel, Pinot gris, harvests of 2016, 2017, 2018, coming from the: Bohotin, Cotești, Cotnari, Huși and Iasi vineyards. The GC-MS methods were utilized to identifing and quantifing the volatile compounds of thies wines.The results obtained being grouped into three categories, namely: higher alcohols, volatile acids and esters. It was found that the higher alcohols have minimum values between $195.07 \mathrm{mg} / \mathrm{L}$ and maximum values of $257.2 \mathrm{mg} / \mathrm{L}$ in Huşi and Bohotin for Feteascea black wine, the volatile acids do not exceed $17.92 \mathrm{mg} / \mathrm{L}$ in Cotnari in Muscat wine Ottonel and the esters reach values of $204.78 \mathrm{mg} / \mathrm{L}$ at the Cotești vineyard in the case of Fetească neagră wine. From the results obtained we distinguish the Feteasca neagră wine with the optimal ratio between the three monitored indicators.
\end{abstract}

KEY WORDS: volatile compounds, GC-MS, Moldova's wines

\section{INTRODUCTION}

The aromatic complex of wines is the main element of their selection by the consumer. Aroma is a very important characteristic in wine (Lengyel 2012). The current trend of winemaking is to produce wines with different aromatic nuances to provide a variety of wines in the developing market. Flavor is known to depend on pedo-climatic conditions, variety of grapes, region, methods of extraction of volatile substances applied in wine production technology, selected yeast strains, intrinsic value of various compounds and precursors, including established winemaking methods and practices. or how it is conditioned and stored (Styger et al. 2011, Lengyel 2012). Volatile compounds have an important role to characterize the aroma. The olfactory thresholds of these compounds may differ considerably, so that some compounds present in the traces may play a key role in the aroma of a wine, while others, although more abundant, may do so to a lesser extent. "Many of the volatile chemical compounds contained in wine can be used as differentiation parameters to determine the origin of the wine" (Stegăruș 2015).

The volatile profile of a wine is influenced by several factors: the grape variety, soil, climatic conditions, the vinification process, during which it can intervene at any stage and the conditions of wine storage (Lengyel 2015, Sacchi et al. 2005).

These flavors are mostly attributed to classes of compounds such as: terpenes, higher alcohols, aldehydes, ketones, esters, fatty acids (Andujar-Ortiz et al. 2009, Wust 2003). The aromatic, volatile compounds of wine are currently in the order of hundreds, this aspect not being fully elucidated until now. We can mention the phenolic and terpenic compounds, the benzene derivatives, the norisoprenoids, the thiols, the carbonyl groups, the methoxypyrazines, generally the polyphenols, the wine chemistry being particularly attractive from this point of view (Waterhouse 2002). In the last years the techniques of quantification of the various elements have led to the identification of many groups of aroma compounds that, even without the threshold of human perception. All these elements, even if they are in a small amount, actively participate in the formation of the aromatic complex of wines. Aroma is one very important factors that determine the quality of the wine and their sensorial character (Villamor et al. 2013). Some of the aromatic compounds are released directly from grape beans, while others are formed during the fermentation and ripening process (Pretorius et al. 2008). The most important aromatic compounds in wine are those that come from the fermentation process, which mainly include higher alcohols and aldehydes, fatty acids and esters. The much aroma characteristics of wine are give by chemical compounds: esters of decanoic acid, hexanoic acid, octanoic acid, isoamyl acetate, isobutyl acetate

(Ferreira et al. 2016). The concentration of volatile compounds differs from one variety to another, being of the order of $\mathrm{mg} / \mathrm{L}$ to a few ng / L, the olfactory perception varies considerably. The red wines content in the early stages of wine life many of monomeric anthocyanins (Alcalde-Eon et al. 2007; Torchio et al. 2011) but are involved in different reactions (copigmentation), polymerization, vinification and further in the aging of the wine) which can change its concentration (Briz-Cid et al., 2014). Vinification involves musts and wines in constant evolution. Vitis-type grapes are relatively rich phenolic compounds, thus that their extraction is an advantage in increasing the polyphenol content in wines. The phenolic content of the wine depends on the raw material and the type of vinification followed, which affects the physical and chemical phenomena and biochemical phenomena (oxidation, degradation, condensation, etc.) (Mulero et al., 2015, Wust 2003). The type and concentration of phenolic compounds in wine depends on the variety of grapes, baking, atmospheric conditions, viticulture and winemaking techniques (RodríguezDelgado et al., 2002). The physical properties and chemical characteristics of the wine

give it the sensory quality and the phenolic compounds are responsible for the bitterness, color, astringency they are an important quality parameter of red wine. Red wines are mainly composed monomeric anthocyanins, derivatives of monomeric anthocyanins and non-anthocyanin phenolic compounds. Thies include flavonols, hydroxylbenzoic acids, flavanols and hydroxycinnamic acids. The bitterness and the astrigency af red wine is a result of flavanols and phenolic acids, and the color is 
insured of the quantity and quality of monomeric anthocyanins ( Lengyel et al. 2015, He et al., 2012b).

Several studies have shown that low temperature favors the synthesis and retention of flavors in the fermentation process. Thus new species of wine yeasts are able to promote a fermentation at a low temperature, the consequence being the aromatic improvement of the wine. Specialized studies explore oenological features of different Saccharomyces species and hybrids relevant to the current wine industry. The techniques used were biochemical in nature, analytical chemistry, including molecular techniques to verify the enzymatic activity, detection, determination of the flavor profile and analysis of the transcriptome during the fermentation period of the wine. Studies show that the production and release of aromas in vinification depends on the strain that carries out the fermentation process but also on the temperature used (Stegăruș et al. 2017).

\section{MATERIALS AND METHODS}

- Busuioaca de Bohotin, Fetească neagră, Muscat Ottonel, Pinot gris wines, harvests of the years 2016, 2017, 2018, from the vineyards: Bohotin, Cotești, Cotnari, Huși and Iași, (the varieties were noted with the acronyms: Busuioaca de Bohotin : BB, Fetească neagră: FN, Muscat Ottonel: MO, Pinot gris: PG)

- GC / FID (Varian 450 GC gas chromatograph coupled with Varian 240 MS, flame ionization detector, Thermo Scientific TG-WAXMS capillary column (Waltham, MA USA) $(60 \mathrm{~m} \mathrm{x}$ $0.32 \times 0.25 \mathrm{pm})$. was developed and published by Stegăruş (2016). This method sought to identify and quantify the following volatile compounds:

Higth Alcohol: 1-Butanol, 2-Methyl-1-Butanol, 4-Methyl-1Pentanol, 1-Hexanol, 3-Methyl-1-Butanol, , 1-Propanol, 1Octanol, Benzyl Alcool, Tyrosol, Isobutyl Alcohol, Isoamyl Alcohol Methionol, 1-Heptanol, 2-Nonanol
Volatile Acids: Isovaleric Acid, Octanoic Acid, Heptanoic Acid, Dodecanoic Acid, Isobutyric Acid, Acetic Acid, Hexadecanoic Acid, Butyric Acid

Esters: Ethyl Octanoate, Ethyl Formate, Ethyl Decanoate, Ethyl Lactate, Isoamyl Acetate, Ethyl Acetate, Diethyl Succinate, Isoamyl Acetate, Hexyl Acetate, Heptyl Acetate, Methyl Octanoate

The standards for the volatile compounds identified and quantified in the present work are of chromatographic purity and come from the Sigma-Aldrich company.

\section{RESULTS AND DISCUSSIONS}

The volatile compounds influence the organoleptic properties of the wine contributing to the formation of the aroma, the volume being in very varied amounts, their combinations conferring originality and uniqueness to each assortment. The studied wines showed accumulations of higher alcohols in amounts ranging in 2016 between 196.07 mg / L in Huși - Fetească neagră and $237.31 \mathrm{mg} / \mathrm{L}$ also in Huși in the case of the Busuioaca de Bohotin assortment (Figure 1). Comparing the vineyards for the same wine assortment, it can be seen that the differences can reach up to $12 \%-18 \%$. The most noticeable difference is in the case of Feteasca black wine, where the values differ by $18 \%$ between the vineyards. In 2017, the values of higher alcohols increase not decelerating amounts below $100 \mathrm{mg} / \mathrm{L}$. The most significant values are noted in the case of Fetească neagră wine, where the value of $257.2 \mathrm{mg} / \mathrm{L}$ was identified. The vineyard is noteworthy as the vineyard where these values are remarkable regardless of the wine range. In the year 2018 Busuioaca de Bohotin presents the most significant accumulations of higher alcohols in all five vineyards, the values reaching a maximum of $255.32 \mathrm{mg} / \mathrm{L}$. In contrast, Muscat Ottonel wine has higher alcohol values even below $100 \mathrm{mg} / \mathrm{L}$ in the case of Cotnari and Huși vineyards.

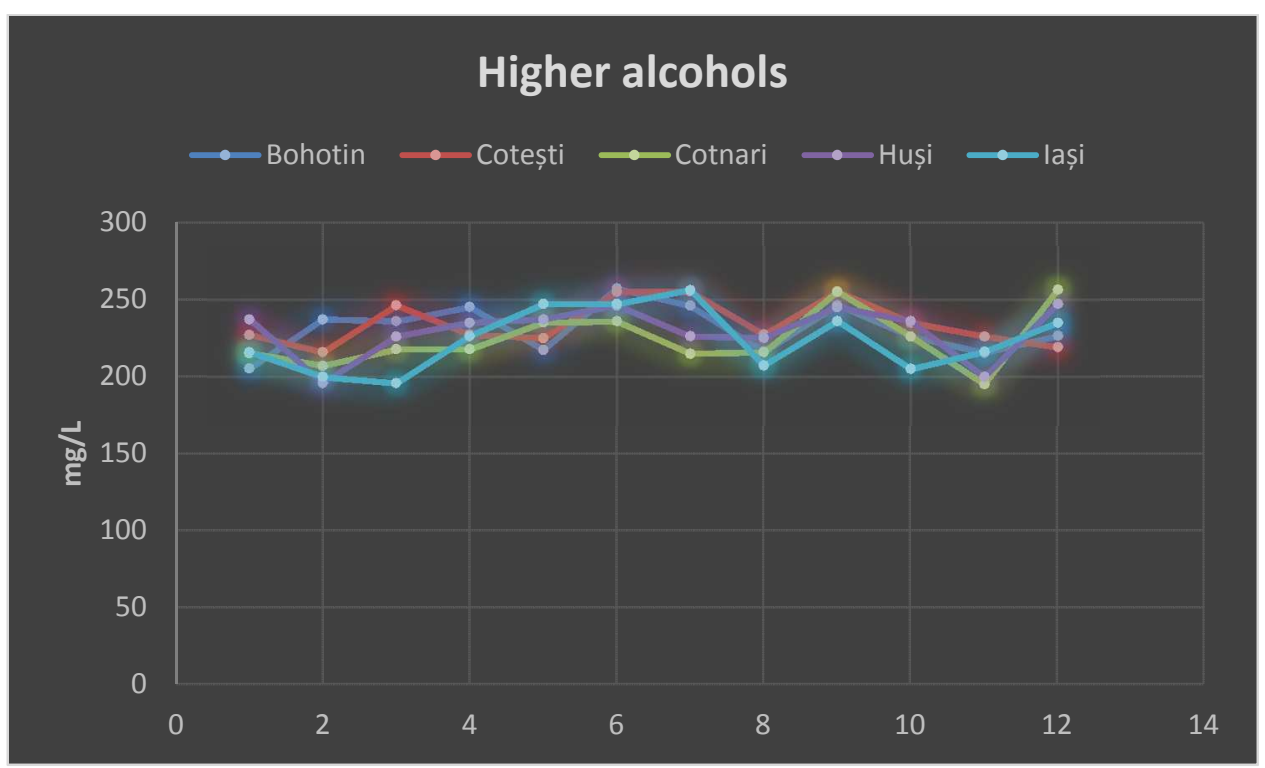

Figure 1. The sum of the higher alcohols identified and quantified in the wines Busuioaca de Bohotin, Feteasca neagra, Muscat Ottonel, Pinot gris, of the years 2016, 2017, 2018, from the Bohotin, Cotești, Cotnari, Huși and Iași vineyards

Volatile acids in wines provide valuable information on acids belonging to the acetic series present in wine in the free state and in the form of salt. As shown in figure 2, the volatile acidity fluctuates around $15 \mathrm{mg} / \mathrm{L}$, with slight increases at the Huşi and Cotești Vineyards in 2016 and 2018, when it reaches $17.3 \mathrm{mg} /$ L. In 2016, the values of volatile acids quantified in the four assortments of wine fall within the limits starting from $15.07 \mathrm{mg}$ / L for Pinot gris from Huși, reaching a maximum of $17.92 \mathrm{mg}$ /
L for Muscat Ottonel wine from Cotnari. In 2017, the range of values found starts from $15.04 \mathrm{mg} / \mathrm{L}$ volatile acidity in the case of Feteasca neagra wine from Cotești and reaches $17.43 \mathrm{mg} / \mathrm{L}$ in the case of Busuioaca de Bohotin wine from the Bohotin. Compared to 2016, the values determined in 2017 are lower on average by $5.6 \%$. Following the evolution of this parameter in 2018 it is noted that the obtained values are around $16 \mathrm{mg} / \mathrm{L}$, a minimum of $15.07 \mathrm{mg} / \mathrm{L}$ volatile acidity in the case of Feteasca 
neagra wine from Cotești and a maximum of $17.27 \mathrm{mg} / \mathrm{L}$ in the case of Pinot gris wine from Huși.

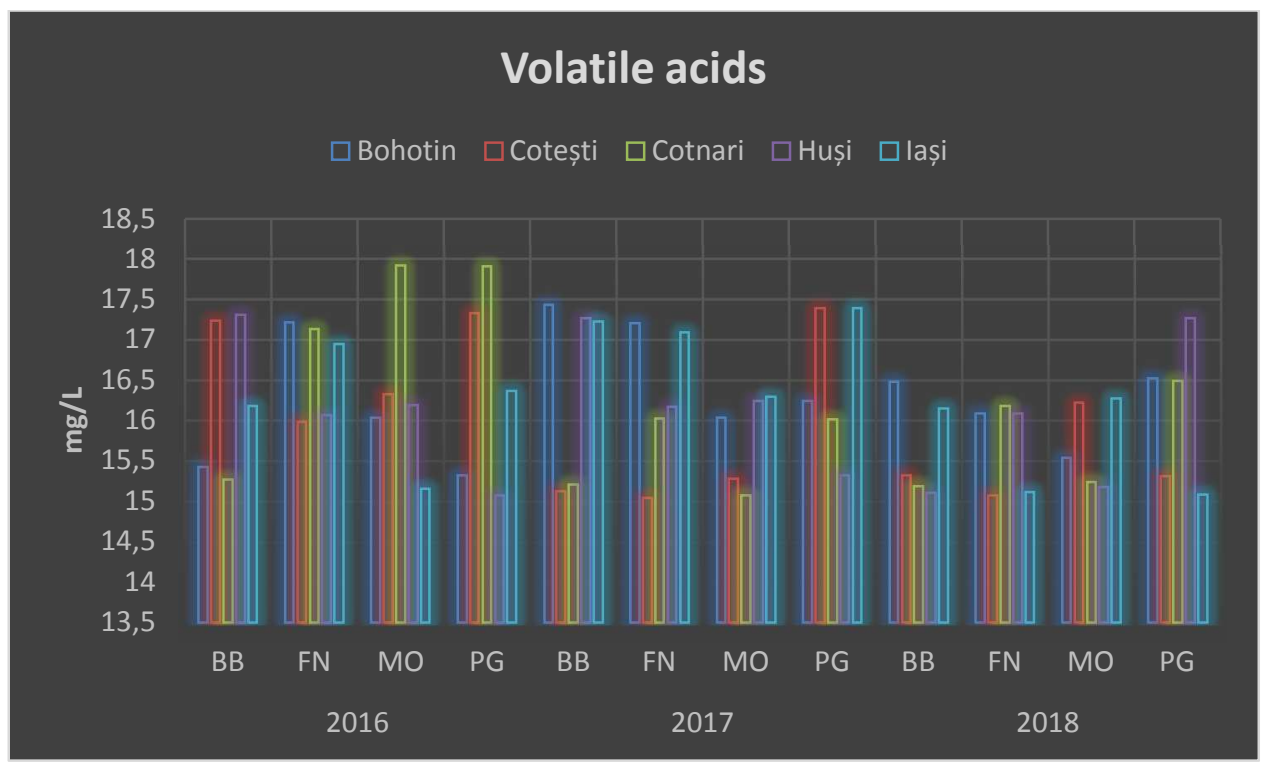

Figure 2. The sum of the volatile acids identified and quantified in the wines Busuioaca de Bohotin, Feteasca neagră, Muscat

Ottonel, Pinot gris, harvests of 2016, 2017, 2018, from the Bohotin, Cotești, Cotnari, Huși and Iași vineyards

As shown in Figure 3 the sum of the esters varies in 2016 between $73.1 \mathrm{mg} / \mathrm{L}$ in the case of the Busuioaca de Bohotin assortment from Huși and a maximum of $132.1 \mathrm{mg} / \mathrm{L}$ in the case of the wine from Cotești, Muscat Ottonel. It is noted that there are major differences between the accumulation of esters in wines from different vineyards. The closest and constant values are noted in the case of Muscat Ottonel wine where in the case of all vineyards the value exceeds $120 \mathrm{mg} / \mathrm{L}$. In the case of Busuioaca de Bohotin wines, these values start at $73.1 \mathrm{mg} / \mathrm{L}$ in Huși, followed by Cotnari with $92.7 \mathrm{mg} / \mathrm{L}$ and Iasi with 98.8 $\mathrm{mg} / \mathrm{L}$. Higher values were obtained in the case of the Bohotin and Cotești vineyards where they are located at a level around $123 \mathrm{mg} / \mathrm{L}$. Feteasca neagră wine has values below $100 \mathrm{mg} / \mathrm{L}$ in all vineyards studied, with the exception of Cotnari where they reach $124.3 \mathrm{mg} / \mathrm{L}$. Pinot gris wine oscillates around 100 $\mathrm{mg} / \mathrm{L}$, reaching a maximum of 111.2 / $111.4 \mathrm{mg} / \mathrm{L}$ in the case of Coteşti and Cotnari vineyards. The year 2017 preserves the diversity of values in the accumulation of esters, starting from $93.5 \mathrm{mg} / \mathrm{L}$ in the case of Busuioaca de Bohotin wine and reaching $204.7 \mathrm{mg} / \mathrm{L}$ in the case of Cotești, Fetească neagră. In 2018, the values of higher quantified alcohols range from 82.9 $\mathrm{mg} / \mathrm{L}$ in the case of Pinot gris wine from Bohotin and $115.2 \mathrm{mg}$ / $\mathrm{L}$ in the case of Iași, the Busuioaca de Bohotin assortment. Muscat Ottonel wine is noticeable in all five vineyards with values above $115 \mathrm{mg} / \mathrm{L}$, while Pinot gris wine oscillates around $100 \mathrm{mg} / \mathrm{L}$.

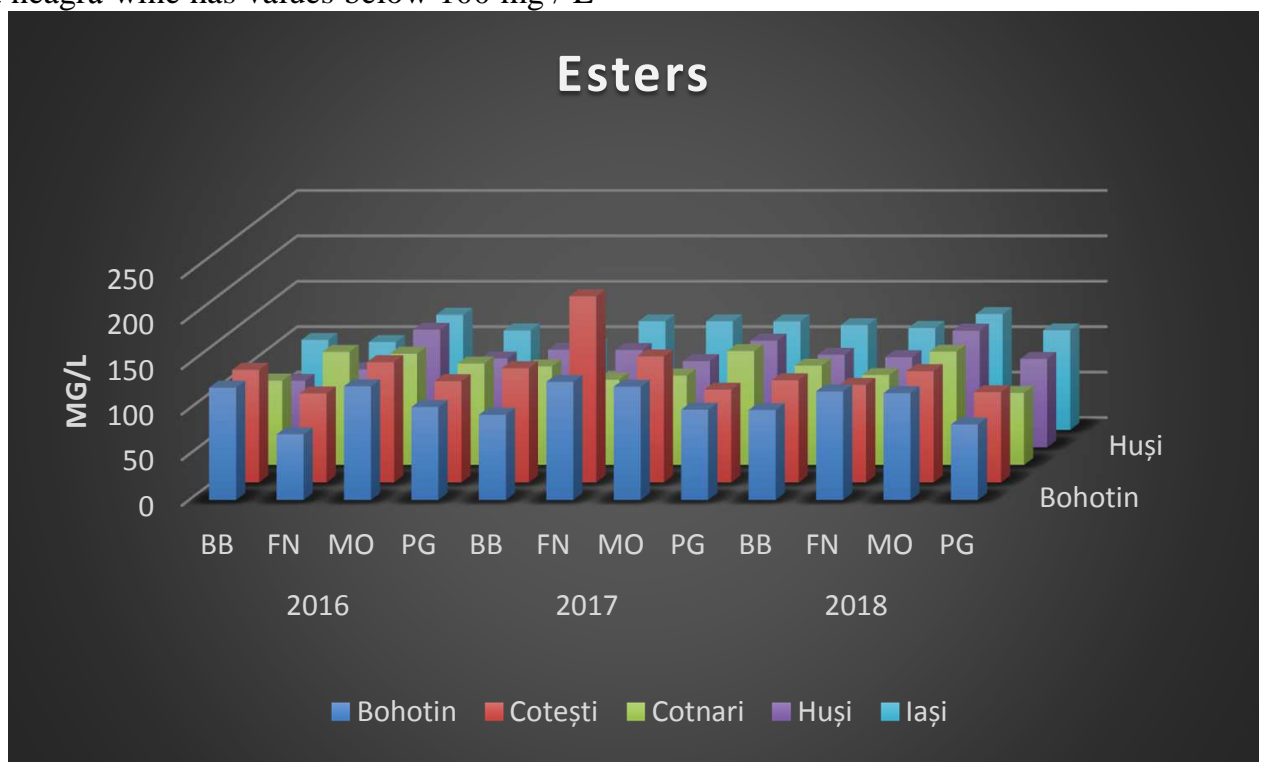

Figure 3. The sum of the esters identified and quantified in the wines Busuioaca de Bohotin, Feteasca neagra, Muscat Ottonel, Pinot gris, harvests of the years 2016, 2017, 2018, from the Bohotin, Cotești, Cotnari, Huși and Iași vineyards

\section{CONCLUSIONS}

Following the analyzes carried out on GC-MS, it was possible to identify more than 35 volatile aromatic compounds, in amounts that can give the selected wines the qualities expected by the manufacturer. The highest weight is given by the esters and higher alcohols, there is a correlation between them. Particularly noteworthy are the ethyl esters that dominate the selected wines, the higher alcohols with the highest weight being the isobutyl and isoamyl alcohol. The years studied were aimed at climate change, so that some of the decelated compounds can be associated with this phenomenon. The fermentative processes 
used by the producers lead to variations in the system of armatic evaluation of the wines, even if we speak of the same assortment. The volatile acidity reflects the concentration in heptanoic, isovaleric, octanoic, dodecanoic, isobutyric, hexadecanoic, butyric but especially acetic acid, printing the wine the specific taste of each vineyard. The differences in value do not exceed acceptable margins of $5 \%-18 \%$, in the case of the determinations made, even if the wines come from different vineyards, the explanation being that the wine-growing area can print these characteristics from the point of view of the pedoclimatic and structural evaluations. The monitored indicators lead to the conclusion that the black Feteasca wine presents an optimal ratio, so that it can be recommended as a local aromatic wine of superior aromatic quality. The aromatic characterization of these wines, the quantification of valuable volatile compounds contributes to the promotion of Romanian wines from the Moldova area, but also offers the opportunity to continue these studies.

\section{REFERENCES}

1. Alcalde-Eon C., Escribano-Bailon M.T., Santos-Buelga C., Rivas-Gonzal J.C., 2007. Identification of dimeric anthocyanins and new oligomeric pigments in red wine by means of HPLC-DADESI/ MS. Journal of Mass Spectrometry, 42, 735e 748

2. Andujar-Ortiz M.V., Moreno-Arribas P.J., Martín-Álvarez M.A., Pozo-Bayón, 2009. Analytical performance of three commonly used extraction methods for the gas chromatography-mass spectrometry analysis of wine volatile compounds, Journal of Chromatography A 1216, (43), 7351-7357

3. Briz-Cid N., Figueiredo-Gonzalez M., Rial-Otero R., Cancho-Grande B., Simal-Gandara J., 2014. The measure and control of effects of botryticides on phenolic profile and color quality of red wines, Food Control 50, 942e948

4. Ferreira V., Fernández-Zurbano P., Valentin D., 2016. Understanding quality judgements of red wines by experts: Effect of evaluation condition, Food Quality and Preference 48, 216-227.

5. He F., Liang N.-N., Mu L., Pan Q.-H., Wang J., Reeves M. J., 2012b. Anthocyanins and their variation in red wines II. Anthocyanin derived pigments and their color evolution. Molecules, 17,(2), 1483-1519

6. Lengyel E., 2012, Primary aromatic character of wines, Acta Universitatis Cibiniensis, Series E: Food Technology, 16, (1), 3-18

7. Lengyel E., 2015, Cercetări privind optimizarea proceselor fermentative în vederea păstrării și consolidării tipicității și autenticităţii vinurilor românești, Ed. Universităţii Lucian Blaga Sibiu
8. Lengyel E., Sikolya L., 2015, The influence of aroma compounds on senzorial traits of wines from the Apold depression, Management of Sustainable Development Sibiu, Romania, 7, (1), 23-28

9. Mulero J., Martínez G., Oliva J., Cermeño S., Cayuela J.M., Zafrilla P, Martínez-Cachá A., Barba A., 2015. Phenolic compounds and antioxidant activity of red wine made from grapes treated with different fungicides, Food Chemistry 180, 25-31

10. Pretorius I.S., Hoj P.B., 2008. Grape and wine biotechnology: Challenges, opportunities and potential benefits, Journal of Biotechnologies, Australian Journal of Grape and Wine Research 11(2):83 - 108

11. Rodríguez-Delgado M.A., González -Hernández G.,Conde-González J.E. and Pérez- Trujillo J.P., 2002. Principal component analysis of the polyphenol content in young red wines, Food Chemistry 78, 523-532

12. Sacchi, K.L., Bisson, L.F., Adams, D.O., 2005. A review of the effect of winemaking techniques on phenolic extraction in red wines, American Journal of Enology and Viticulture, 56(3), 197-206

13. Stegarus D.I., 2015. Defining and evaluating the authenticity and typicality from some local varieties from consecrated wine regions, Doctoral Dissertation summary, Sibiu, Faculty of Agricultural Sciences, Food Industry and Environmental Protection

14. Stegăruș D., Lengyel E., Ionete R., 2017. The influence of fermentation temperature in ester accumulation in wines originating from the wine field of Apoldu de jos, Romania, Conference proceeding, 17-International Multidisciplinary Scientific Geoconference, SGEM 2017, Albena Bulgaria, Advances in Biotechnology, 1137-1143

15. Styger G., Prior, B., Bauer F. F., 2011. Wine flavor and aroma. Journal of Industrial Microbiology \& Biotechnology, 38(9), 1145-1159

16. Torchio F., Río Segade S., Gerbi V., Cagnasso E., Rolle L., 2011. Changes in chromatic characteristics. and phenolic composition during winemaking and shelf-life of two types of red sweet sparkling wines, Food Research International, 44, 729-738

17. Villamor R. R., Evans M. A., Ross C. F., 2013. Effects of ethanol, tannin, and fructose concentrations on sensory properties of model red wines, American Journal of Enology and Viticulture, 64, 342-348

18. Waterhouse A. L., 2002. Wine phenolics, Annals of New York Academy of Sciences, 957, 21-36

19. Wüst M., 2003. Zur Biochemie des sortentypischen Weinaromas, Chem.Unserer Zeit 1/37, 8-17 